\title{
A TIEGCM Numerical Study of the Source and Evolution of Ionospheric F-region Tongues of Ionization: Universal Time and Interplanetary Magnetic Field Dependence
}

Jing Liu ${ }^{1}$, Wenbin Wang ${ }^{1}$, Alan Burns ${ }^{1}$, Libo Liu ${ }^{2}$, and Joe McInerney $^{1}$ 


\section{Abstract}

32 The National Center for Atmospheric Research Thermosphere-Ionosphere

33 Electrodynamics General Circulation Model (TIEGCM) has been employed to

34 systematically study the source and evolution of the ionospheric F-region Tongue of

35 Ionization (TOI), which is electron density enhancement in the polar region. The model is

36 run for different Universal Times (UT), season and Interplanetary Magnetic Field (IMF)

37 conditions. It is found that: (1) The TOI formation is critically dependent on UT,

38 preferentially near 2000 UT in the Northern Hemisphere (NH) and near 1600 UT in the

39 Southern Hemisphere (SH). These are the intervals when the high-latitude ion convection

40 throat is closer to the middle-latitude high plasma density source region, so that more

41 plasma can be directly transported into the polar cap region; (2) this different UT

42 dependence between the two Hemispheres occurs, not only because of the different

43 separation of the magnetic poles from the geographic poles in the two hemispheres, but

44 also because of the UT dependence of the mid-latitude source locations (local time,

45 latitude) and the magnitude of plasma density enhancements; (3) the TOI is generally

46 stronger in the $\mathrm{SH}$ than it is in the $\mathrm{NH}$, and in winter than in summer; (4) IMF By

47 operates in the opposite sense in the two hemispheres in terms of the TOI pattern such

48 that positive/negative IMF By tends to deflect the TOI toward the morning/afternoon

49 sector in the NH. The opposite condition occurs in the SH. 


\section{1. Introduction}

59 The Interplanetary Magnetic Field (IMF) components of $\mathrm{Bz}$ and By have great

60 influences on the polar ionosphere and thermosphere since IMF Bz determines the cross

61 polar cap potential and ion convection pattern, and IMF By controls the dawn-dusk

62 asymmetry of this ion convection. There are a number of papers devoted to studying IMF

63 By effects on the polar ion convection pattern [e.g., Heppner, 1977; Heelis, 1984;

64 Weimer, 1995, 2005; Ruohoniemi and Greenwald, 2005]. Generally speaking, a large

65 positive (negative) IMF By tends to increase the dusk (dawn) convection cell relative to

66 the convection pattern with small By in the Northern Hemisphere (NH), and the opposite

67 effect occurs in the Southern Hemisphere (SH). The IMF Bz and By components also

68 have important impacts on high-latitude Joule heating, neutral circulation through ion-

69 neutral collision, neutral composition (e.g., $\mathrm{O} / \mathrm{N}_{2}$ ), neutral density, and electron density

$70 \quad$ [e.g., Thayer et al., 1987; Immel et al., 1997; Richmond et al., 2003; McHarg et al., 2005;

71 Liu et al., 2012a]. McHarg et al. [2005] investigated the high-latitude Joule heating

72 response to different IMF conditions based on the NH Joule heating pattern derived from

73 data assimilation and concluded that hemispheric-integrated Joule heating increases with

74 the IMF magnitude during southward IMF conditions, and the IMF By effect on the Joule

75 heating pattern is unremarkable. Immel et al. [1997] investigated the IMF By effects on

76 the far-ultraviolet dayglow observed by the Dynamics Explorer-1 imaging photometer

77 and demonstrated that there was a dependence of the $6300 \AA$ (O I) dayglow brightness on

78 the sign of By. IMF dependence of the high-latitude ionosphere has also been examined

79 with theoretical models [e.g., Roble et al., 1988; Crowley et al., 2006]. Roble et al. [1988]

80 ran the National Center for Atmospheric Research (NCAR) Thermospheric General 
81 Circulation Model (TGCM) for positive IMF By conditions and compared the results

82 with the Dynamics Explorer-2 neutral wind data, revealing a By dependent mechanism

83 that can transport the neutrals from the $\mathrm{NH}$ polar cap to middle latitudes at favorable

84 local times. Crowley et al. [2006] studied IMF By effects on polar thermospheric neutral

85 density and composition using NCAR Thermosphere Ionosphere Mesosphere

86 Electrodynamics General Circulation Model (TIMEGCM) results. They showed that

87 there is a clockwise rotation of the convection potential pattern, neutral wind, density,

88 and composition as IMF By changes from negative to positive.

89 The offset between the geomagnetic and geographic latitudes might give rise to a

90 systematic UT/longitude dependence of high latitude ionospheric and thermospheric

91 phenomena during both geomagnetically quiet and disturbed conditions [Gasda and

92 Richmond, 1998; Sojka et al., 1994, 2012; Xu et al., 2013]. de la Beaujardiere et al.

93 [1985] studied the nighttime F-region density enhancements measured by EISCAT,

94 Chatanika and Millstone Hill Incoherent Scatter Radar (ISR) observations during solar

95 maximum. They showed that those density enhancements exhibited pronounced UT

96 effects, which can be explained by the offset between the geographic and geomagnetic

97 poles. Sojka et al. [2012] performed a numerical simulation of the longitudinal

98 dependence of storm-time mid-latitude dayside Total Electron Content (TEC)

99 enhancements using the Utah State University Time Dependent Ionospheric Model

100 (TDIM) and found that this enhancement favors the American sector. Xu et al. [2013]

101 revealed strong longitude variations under geomagnetic quiet conditions in the daily

102 mean neutral density measured by CHAMP and GRACE satellites during the years 2003-

1032008 and attributed these longitudinal structures to heating of magnetospheric origin. 
104 There are persistent electron density enhancements at high latitudes, individually 105 referred to as a Tongue of Ionization (TOI) or polar cap patch. A TOI is a high latitude,

106 large-scale $(\sim 1000 \mathrm{~km})$ phenomenon that occurs regularly. It is a "tongue"-like high

107 electron density structure that is elongated in the noon-midnight direction. A polar cap

108 patch is a small-scale or medium-scale discrete high plasma density (at least double the

109 background density) structure with a spatial scale of 100-1000 km [Carlson, 2012]. Liu et

110 al. [2015] compared TOI occurrence at different UTs in the 14 October 2012

111 geomagnetic storm and postulated that the occurrence of TOIs depends on UT when

112 geomagnetic activity was moderate. Sojka et al. [1994] studied the UT dependence of

113 polar cap patches in the NH polar ionosphere by changing the IMF By direction using the

114 TDIM. Their model revealed that patch intensities are stronger between 2000-2400 UT

115 and absent between 0800-1200 UT in the winter solstice. Since both IMF and UT

116 regulate high-latitude plasma flow, neutral wind, neutral composition and density, it is

117 anticipated that the TOI depends on the equatorward expansion of polar ion convection

118 and that poleward plasma transport may also have a strong association with TOIs. Several

119 questions arise naturally here: what are the UT and IMF dependencies of TOIs? Is the UT

120 dependence of TOI simply a consequence of the UT variations of the geographic location

121 of the magnetic pole and ion convection; that is, stronger/weaker TOIs occur when the

122 magnetic pole and convection are tapped sunward/toward midnight? Most recently,

123 David et al. [2016] statistically analyzed the seasonal and UT dependence of polar cap

124 patches based on GPS TEC data during 2009-2015. It will be fruitful to make a thorough

125 data-model comparison to give a complete picture of the IMF and UT dependence of

126 TOIs. To date, no first-principles modeling has been performed to fully examine the IMF 
127 and UT effects on TOIs as well as the association with polar cap patches. In this paper,

128 we address this issue by deploying the state-of-the-art, high-resolution NCAR

129 Thermosphere-Ionosphere-Electrodynamics General Circulation Model (TIEGCM) to

130 study the occurrence and intensity of TOIs at different UTs under different IMF Bz and

131 By conditions. The remainder of this article will be arranged as follows. Numerical

132 experiment settings will be explained in the section 2. The UT, IMF, seasonal and solar

133 activity dependence of TOIs will be introduced in the section 3, followed by the

134 discussion and summary.

135

136 2. Numerical Experiment Settings

137 The NCAR TIEGCM is a time dependent, 3-dimensional, thermosphere-ionosphere 138 coupled model solving the fully coupled, nonlinear, hydrodynamic, thermodynamic, and 139 continuity equations of the neutral gas self-consistently with the ion energy, ion

140 momentum, and ion continuity equations as well as the neutral wind dynamo [Roble et

141 al., 1988; Richmond et al., 1992; Qian et al., 2014]. The model resolution is $2.5^{\circ}$ in

142 latitude and longitude and has 60 pressure surfaces in altitude ranging from $97 \mathrm{~km}$ to 500

$143 \mathrm{~km}$, with a vertical resolution of $1 / 4$ scale height. This high-resolution version of the

144 TIEGCM has a better capability to resolve high-latitude ionospheric structures and

145 responses. For example, Wang et al. [1999] compared the high- and low-resolution model

146 results from the Thermosphere-Ionosphere Nested Grid (TING) model, which is an

147 extension of the thermosphere-ionosphere general circulation model (TIGCM), and

148 revealed that the high-resolution model produces a well-defined polar cap TOI and coarse

149 resolution model tends to smooth out the patches and TOI. The input parameters for the 
150 TIEGCM are solar EUV and UV spectral fluxes, parameterized by the solar F10.7 cm

151 index, and high latitude auroral particle precipitation and convection electric fields,

152 which are specified by the Weimer model [Weimer, 2005]. The amplitudes and phases of

153 tides from the lower atmosphere are specified by the global-scale wave model at the

154 model's lower boundary [Hagan and Forbes, 2002]. In this paper, we present the results

155 of numerical experiments for September equinox at solar medium conditions

156 (F10.7=120). All model runs start from the initial state of IMF $B z=0$ and IMF By $=0$ for

15724 hours to reach a steady state. Then we change IMF Bz abruptly from 0 to $-10 \mathrm{nT}$ at

158 different UTs to investigate the UT dependence of the high latitude ionosphere response

159 to IMF changes. In order to reveal IMF effects on the high latitude ionosphere, we sort

160 IMF By and Bz at the UT when the TOI is most prominent.

161

162 3. Results

163 3.1 Evolutions and UT Dependence of TOIs

164 Figure 1 shows the evolution of ionospheric $\mathrm{F} 2$ region peak density $\left(\mathrm{NmF}_{2}\right)$ for the $\mathrm{NH}$

165 in geographic latitude (above $40^{\circ}$ ) and local time (LT) coordinates. The superimposed

166 electrostatic potential is from the Weimer model [Weimer, 2005]. As IMF Bz changes

167 from 0 to $-10 \mathrm{nT}$ at $0000 \mathrm{UT}$, a pronounced two-cell plasma convection pattern expands

168 toward lower latitudes. Two hours later at $0200 \mathrm{UT}$, positive storm effects (enhanced

169 electron densities) appear at middle latitudes in the afternoon sector. The positive storm

170 effects become stronger and expand to higher latitudes in the following 2 hours. At 0300

171 UT, a TOI appears between $70^{\circ}$ and $80^{\circ}$ geographic latitude at about $1300 \mathrm{LT}$ along the

172 plasma anti-sunward convection channel that runs from noon to midnight. This TOI 
173 becomes stronger with UT until 0600 UT. Compared with NmF2 at 2300 UT, the high-

174 latitude low electron density region (the blue colored region, negative storm effect) starts

175 to expand towards the early morning sector and afternoon sector after IMF $B_{z}$ turning

176 southward at 0000 UT. For instance, the red-blue separatrix at 2300 UT locates at round

$1770600 \mathrm{LT}$, whereas it moves gradually to about $1000 \mathrm{LT}$ at $0700 \mathrm{UT}$. The last panel of

178 Figure 1 gives NmF2 at $0700 \mathrm{UT}$, when a strong negative storm effect occurs at high 179 latitudes, especially in the post-midnight to early morning sector and the TOI becomes 180 weaker than it was from 0300 UT to 0600 UT. In addition, the magnetic pole and ion 181 convection pattern rotate counterclockwise with respect to the geographic pole.

182 Figure 2 is for the $\mathrm{SH}$ in the similar format of Figure 1. Similar to the NH, both the

183 convection pattern and the magnetic pole rotate counterclockwise with UT with respect to 184 the geographic pole. The latitudinal distance between the magnetic and geographic poles

185 is larger in the $\mathrm{SH}$ than that in the $\mathrm{NH}$, which makes the UT effect on polar ion 186 convection larger in the $\mathrm{SH}$. The $\mathrm{SH}$ convection pattern is more displaced towards the 187 daytime ionization between 2300 and 0700 UT in Figure 2. The middle latitude positive 188 storm effects in the noon-2000 LT sector occur at 0200 UT, which is earlier than they 189 were in the NH case. A TOI occurs at 0200 UT and becomes stronger at $0400 \mathrm{UT}$. TOIs 190 only appear in limited regions and do not extend into the nighttime. As shown in Figures

1911 and 2, the TOI signatures are stronger 4 hours after the southward IMF Bz turning.

192 Figure 3 shows the UT dependence of NmF2 for the NH in geographic latitude (the 193 outer circle is 40 degrees) and local time coordinates after imposing IMF Bz $=-10 \mathrm{nT}$ for 1944 hours for a number of different starting times. Universal Times listed above each panel 195 are the simulation starting time plus 4 hours. There is a clear UT dependence of the 
196 middle latitude high electron density "reservoir". In addition, relative locations between

197 the two-cell plasma convection and the geographic pole also change with UT. For

198 example, the positive storm effects in the noon-2000 LT sector are stronger and wider in

199 LT at 2000 UT than at earlier or later UT hours. The dayside convection throat is located

200 in the morning sector during 0400-1200 UT, whereas it is located at the afternoon sector,

201 closer to the afternoon positive storm effect region during 1600-2400 UT. Furthermore,

202 the high-latitude plasma convection pattern in the throat region moves to about $58^{\circ}$

203 geographic latitude at $2000 \mathrm{UT}$, but it locates at $70^{\circ}$ geographic latitude at $0400 \mathrm{UT}$.

204 Because of the favorable relative location between the high electron density reservoir at

205 middle latitudes caused by the positive storm effects in the afternoon sector and the dusk

206 convection cell and the throat region, the TOI is stronger at around $2000 \mathrm{UT}$, and weakest

207 at around 0800 UT. The UT variation of the positive storm effects is another interesting

208 phenomenon and will be studied in a separate publication.

209 Figure 4 is the same as Figure 3 but for the SH. SH TOIs are generally stronger than

$210 \mathrm{NH}$ TOIs (see Figure 3 for the $\mathrm{NH}$ ). In the $\mathrm{SH}$, the two-cell convection throat is located

211 in the afternoon sector between 0400-1600 UT and in the morning sector between 2000-

2122400 UT. In addition, the high electron density region stretches further across the polar

213 cap towards the nightside at 1600 UT, as compared to other UTs. As a result of the

214 overlap between the two-cell convection pattern and the middle-latitude high plasma

215 density reservoir, the TOI intensity is strongest at about $1600 \mathrm{UT}$, and weakest in the

216 early morning and near midnight UT hours.

217

$218 \quad 3.2$ Season dependence of UT effects 
219 In order to investigate the seasonal dependence of UT effects on TOI, Figure 5 shows

220 seasonal variations of $\mathrm{NH} \mathrm{NmF2}$ as a function of geographic latitude and local time at

221 different UTs. At equinox, TOIs have similar structures and intensities. TOIs, having

222 similar shapes, are much weaker in summer that they are in other seasons. TOI is hardly

223 discerned during 0400-1600 UT in summer, which has almost the same local time

224 dependence but different seasonal dependence with respect to the polar cap patch as

225 revealed by Sojka et al. [1994] and David et al., [2016]. They showed that polar cap

226 patches are weakest or disappear during 0600-1300 UT in winter. We will interpret this

227 discrepancy in the discussion part. To avoid repetition, we do not show the $\mathrm{SH}$, in which

228 TOIs have similar seasonal dependence.

\section{$230 \quad 3.3$ IMF Dependence of TOI}

231 Figure 6 illustrates the IMF By effects on TOIs in the two hemispheres for southward

232 IMF Bz conditions. We set IMF $\mathrm{Bz}=-10, \mathrm{By}= \pm 10$, and examined the model results

233 after running the simulation for 4 hours. The top and bottom panels are for the $\mathrm{NH}$ at

$2342000 \mathrm{UT}$ and SH at $1600 \mathrm{UT}$, respectively. The reason for choosing these two UTs is that

235 the TOIs are more prominent at those UTs. As can be seen from this figure, the dusk

236 plasma convection cell is larger relative to the dawn counterpart in the $\mathrm{NH}$, and the throat

237 region locates at an earlier local time when By is positive (upper right panel), compared

238 to the convection pattern for the By negative case (upper middle panel). Thus, the TOI is

239 stronger and pushed more toward the duskside and middle latitudes when By is negative.

240 For positive By, the TOI is weaker in the $\mathrm{NH}$ because the convection convergence region

241 is further away from the afternoon electron density peak, so it is more difficult to 
242 transport the plasma from the afternoon sector into the throat region. The opposite

243 conditions apply for the SH. The dawn cell is much better defined, and the TOI moves

244 closer to the pre-midnight sector for positive By, compared with what it does for the

245 negative By. One common feature in both hemispheres is that TOI intensity tends to be

246 weaker when IMF By has a magnitude that is close to that of $\mathrm{Bz}$ in our simulations. The

247 reason for this is that IMF By tends to twist the two-cell convection pattern making it

248 more difficult to advect the plasma into and across the polar cap. Further studies are

249 needed to fully evaluate the effect of relative strength between $\mathrm{By}$ and $\mathrm{Bz}$ on the

250 occurrence, location, and intensity of TOIs.

251 Figure 7 depicts the IMF Bz effects on the TOI in the two hemispheres. We set IMF Bz

$252=-10,-5$ and $10 \mathrm{nT}$ with a constant IMF By $(\mathrm{IMF}$ By $=0)$. The middle latitude

253 ionospheric $\mathrm{NmF}_{2}$ was less increased, the two-cell convection pattern is more confined to

254 high latitudes, and the TOI is weaker when IMF Bz has a smaller southward component.

255 The convection is much weaker and more distorted during northward IMF conditions

256 than during southward conditions. For northward IMF Bz, the convection exhibits a more

257 complex structure and has multi-cells. No obvious TOI can be observed under northward

258 IMF conditions. In the SH, the electron density is smoothly distributed. For both

259 hemispheres, the convection patterns are confined to higher latitudes and away from the

260 middle latitude source region for northward IMF Bz conditions. At the same time, there

261 are no or small positive storm effects to build up the source. Therefore, the TOI is thus

262 non-exist or very weak.

263 Figure 8 shows the solar activity dependence of the TOI for southward IMF Bz at 2000

264 UT at September equinox. $\mathrm{NmF}_{2}$ is overall larger at higher solar activity. Generally, TOIs 
265 are weaker and become wider at low solar activity $(\mathrm{F} 10.7=70)$ than they are at the

266 higher solar activity $(\mathrm{F} 10.7=180)$. This agrees with the study of David et al. [2016], in

267 which they show tongue-to-background ratio is much lower at solar minimum. In the NH,

268 TOI disappears at the lowest solar activity $(\mathrm{F} 10.7=70)$. In the SH, TOIs are similar in 269 shape for different solar activities.

270

271 4. Discussion

272 4.1 UT and IMF Dependence of TOI Intensity

273 The expanded two-cell ion convection pattern under southward Bz conditions

274 transports the plasma from mid-latitudes into the high latitudes to form the TOI structure.

275 There are three main factors contributing to the UT dependence of TOIs, including:

276 (1) The UT variations of the magnetosphere reconnection between the solar wind

277 magnetic field and the geomagnetic field at the magnetopause due to the UT variation of

278 the geomagnetic tilt angle. This affects the cross polar cap potential, $\mathbf{E} \times \mathbf{B}$ plasma drifts

279 and the dynamics of the TOI [Weimer, 1996, Deng et al., 2006]. Taking the SH as an

280 example in Figure 9, the positive and negative potential cells rotates around the

281 geographic pole with UT, and shifts more toward middle latitudes near noon at 0400 UT

282 and at midnight at 1600 UT. The $\mathbf{E} \times \mathbf{B}$ upward ion drift peaks change with UT and vary

283 from two peaks at 0000 UT to a single peak at 2000 UT.

284 (2) The UT variations of the middle latitude high plasma density reservoir. The latitudinal

285 locations of maximum electron density and the magnitudes of the electron density

286 enhancement change with UT (Figures 3 and 4). In the NH, maximum electron densities

287 typically occur at around $40-50^{\circ}$ at different local times, whereas they can appear at a 
288 larger latitude range from $40^{\circ}$ to $60^{\circ}$ in the SH. Liu et al. [2016b] showed that the

289 enhanced plasma densities at subauroral middle latitudes around noon are mainly caused

290 by the $\mathbf{E} \times \mathbf{B}$ upward ion drifts that lift the ionosphere to higher altitudes where chemical

291 recombination is slower. Sojka et al. [2012] studied the longitudinal dependence of

292 storm-time middle latitude electron density enhancement and ascribed this to longitudinal

293 variations of both the neutral winds and the electric fields. The longitudinal dependence

294 of neutral wind effects may either enhance or counteract the effect of the expanded high-

295 latitude convection electric fields.

296 (3) The UT variations of the relative position between the twin-cell polar plasma

297 convection, especially for the throat region, and the middle latitude plasma reservoir.

298 This arises from the relation between the two principal coordinate systems of ionosphere-

299 magnetosphere interaction: solar geomagnetic coordinates in which the ion convection

300 pattern occurs and solar-terrestrial coordinates (geographic latitude/LT) in which solar

301 heating produced plasma generally resides. These coordinate systems vary with respect to

302 one another with UT, determining the amount of electron transport from mid-latitudes to

303 high latitudes. It would be expected that the UT at which the noon portion of the auroral

304 oval is at its lowest geographic latitude should correspond roughly to the time when the

305 plasma drifting across the polar cap contains the largest electron densities. Currently, the

306 south and north magnetic poles are located at about $64^{\circ} \mathrm{S}, 140^{\circ} \mathrm{E}$ and $81^{\circ} \mathrm{N}, 110^{\circ} \mathrm{W}$ in

307 geographic coordinates, respectively, which corresponds to 0300 UT and 1900 UT at

308 noon. However, the expected relationship between the UT when the auroral oval at local

309 noon is at its lowest geographical latitude and the strength of the tongue does not occur in

310 the SH. In this case, the TOI is stronger at $1600 \mathrm{UT}$ when the mid-latitude positive storm 
311 effects are stronger and at higher latitudes than they are at 0400 UT when the above-

312 mentioned condition is met. Thus, in the $\mathrm{SH}$, the ion convection throat region is most

313 efficient at tapping plasma into the polar cap to form a TOI in the presence of an intense

314 plasma reservoir at a relatively higher geographic latitude even though the magnetic pole

315 and almost the entire polar convection pattern are located on the nightside. On the other

316 hand, the NH does behave as expected. That is, the TOI is stronger at 2000 UT when the

317 convection pattern is closer to the high electron density region. To some extent, the IMF

318 By and UT effects on TOIs operate in a similar way by modifying the relative location

319 between the two-cell convection configuration, including the convection throat region,

320 and the middle latitude high plasma density reservoir. In the NH, as shown in Figure 5, it

321 is interesting to note that, for negative By, the dawn cell ion convection velocities

322 become faster than for zero IMF By condition. When IMF By is positive, the dusk cell is

323 larger relative to its dawn counterpart than it is when By is negative. This change in IMF

324 By direction also shifts the dayside plasma convection entry point to an earlier local time.

325 The plasma density is larger at around $1400 \mathrm{LT}$, which is closer to the entry local time for

326 negative IMF By than that for positive IMF By, which facilitates the poleward plasma

327 transport. Thus, the NH TOI is stronger during negative IMF By than that during the

328 positive IMF By conditions. Another process may also contribute to a weaker TOI for the

329 positive By case. The negative storm effects (decreased electron densities) caused by

330 neutral composition changes typically commence in the post midnight and early morning

331 sector at high latitudes [Prolss, 1995; Liu et al., 2010]. These negative storm effects tend

332 to destroy or weaken the TOI. 


\section{$334 \quad$ 4.2 Seasonal Dependence of UT Effects on TOI Intensity}

335 Our NH results showed that TOIs are weaker or almost disappear in summer, which is

336 in general agreement with Sojka et al. [1994] and David et al. [2016]. Sojka et al. [1994]

337 used the convection pattern of Heppner and Maynard [1987] as a driver to TDIM to

338 investigate the UT and seasonal dependence of TOI and patches under moderate

339 geomagnetic disturbed conditions $(\mathrm{Kp}=3.5)$ at solar maximum $(\mathrm{F} 10.7=210)$. They

340 showed that summer hemisphere TOIs/patches disappear during the 0600-1300 UT and

341 patches have the largest intensity in winter between 2000-2400 UT. Based on GPS TEC

342 maps of the Northern Hemisphere from the years 2009 to 2015, David et al. [2016]

343 concluded that TOIs or patches were absent for winter days from about 0500-1200 UT. It

344 should be cautioned to make a direct comparison between our results and previous two

345 results that are drawn from samples at a fixed local time $(\sim 23 \mathrm{LT})$ and close to magnetic

346 pole. The common features are that TOIs/patches are strongest at around $2000 \mathrm{UT}$ in

347 winter hemisphere. This could be related to the stronger plasma source in winter. It would

348 be expected that daytime mid-high latitude electron density is larger in summer than

349 winter given the fact that dayside ionosphere electron content has a strong dependence on

350 solar zenith angle. However, middle latitude winter anomaly is a phenomenon in which

351 F2 region electron density is larger in the winter hemisphere than that in the summer

352 hemisphere [e.g., Rishbeth and Garriott, 1969; Burns et al., 2014]. This winter anomaly

353 brings about larger electron density in the winter hemisphere allowing more plasma

354 transport from the middle latitude ionosphere source region into the polar cap to form

355 TOI or patch. Our current results were drawn from the geomagnetic storm condition

356 (constant IMF $\mathrm{Bz}=-10 \mathrm{nT}$ ). As shown in Figures 1 and 2, positive storm effects are 
357 gradually built up at middle latitudes, which have a strong seasonal dependence. Positive

358 storm effects on the dayside are more likely to occur in the winter than in the summer,

359 which can be viewed as an exaggeration of geomagnetic quiet time winter anomaly. The

360 daytime $O / N_{2}$ at high latitudes suffers more reduction in the summer hemisphere than in

361 the winter hemisphere as a consequence of a larger joule heating [Liu et al., 2012]. Zonal-

362 mean summer-to-winter transequatorial winds facilitate the neutral composition

363 equatorial propagation in summer and hinder it in winter. In addition, the neutral winds

364 tend to converge at middle latitudes in the winter hemisphere, resulting in an increase in

$365 \mathrm{O} / \mathrm{N}_{2}$ and thus increase electron density there. The storm-time higher middle latitude

366 daytime electron density in the winter hemisphere is favorable for generating TOI.

368 4.3 Hemispheric Asymmetry of TOI Intensity

369 The hemispheric asymmetry of TOI intensity is probably caused by the difference of

370 the location of the magnetic poles relative to the geographic ones in the northern and

371 southern hemispheres. The northern magnetic pole is closer to the northern geographic

372 pole than the southern magnetic pole is to the southern geographic pole. The geographic

373 latitude of the southern magnetic pole is near $64^{\circ} \mathrm{S}$, whereas the northern magnetic pole is

374 at about $81^{\circ} \mathrm{N}$ geographic latitude. Because the southern magnetic pole is located more

375 toward geographic midlatitudes, the auroral region in the SH can have relatively smaller

376 solar zenith angles than the auroral region in the $\mathrm{NH}$ in the daytime (and conversely has

377 larger solar zenith angles 12 hours later). Thus, when the solar zenith angle is small,

378 ionospheric plasma densities caused by solar ionization are larger in the auroral region of

379 the SH. This solar zenith angle dependence of electron densities in the auroral region is 
380 complicated by the longitudinal dependence of electric field induced upward plasma

381 drifts as mentioned earlier (Section 4.1). The magnetic field intensity in the $\mathrm{SH}$ is

382 generally weaker than that in the $\mathrm{NH}$, which could produce larger vertical ion drift

383 velocities $\left(\mathbf{V}=(\mathbf{E} \times \mathbf{B}) / \mathrm{B}^{2}\right)$ and electron density enhancements, as suggested by Heelis et al.

384 [2009]. For instance, in the South Atlantic Magnetic Anomaly region, because of the

385 weak magnetic filed intensity, the maximum $\mathrm{NmF} 2$ values are larger in the $\mathrm{SH}$ in Figures

3864 and 6-7. These two factors (relative smaller zenith angles and larger upward drifts)

387 increase plasma contents for the plasma source region for TOI. Therefore, the extended

388 polar convection in the Southern Hemisphere, which is located more toward middle

389 latitudes, is efficient at bringing the plasma from the mid to the high latitudes.

391 5. Conclusions

392 Based on the TIEGCM simulations of occurrence and intensity of TOIs and patches

393 under different IMF and UT conditions, the main results are the following: (1) TOI

394 intensity shows a clear UT dependence and is more prominent during 1600-2000 UT in

395 the NH and 1200-1600 UT in the SH; (2) The UT and IMF orientation dependence of the

396 TOI is different between the Northern and Southern hemispheres because of the different

397 separations of the magnetic poles from the geographic poles in the two hemispheres and 398 the different locations of the plasma source region for TOI; (3) IMF By modifies the 399 plasma convection and TOI pattern in a way that positive/negative IMF By tends to shift 400 the throat region toward the dawn/dusk side in the NH. The opposite condition holds in 401 the SH; generally speaking, larger IMF By magnitude tends to decrease the TOI intensity; 
than in the $\mathrm{NH}$. The TOI is more salient in the $\mathrm{SH}$ than in the $\mathrm{NH}$.

404

405

406

407

408

409

410

411

412

413

414

415

416

417

418

419

420

421

422

423

424

425

426

427

428

429

430

431

432

433

434

435

436

437

438

439

440

441

442

443

444

\section{Acknowledgements}

The National Center for Atmospheric Research is sponsored by the National Science Foundation. This research is also supported by National Natural Science Foundation of China (41304128, 41231065, and 41321003), National Key Basic Research Program of China (2012CB825604) and the projects of Chinese Academy of Sciences (KZZD-EW01-3). The data from TIEGCM can be accessible upon request (jingliu@ucar.edu).

\section{References}

Anderson, D., J. Buchau, and R. Heelis (1988), Origin of density enhancements in the winter polar cap ionosphere, Radio Sci., 23(4), 513-519, doi: 10.1029/RS023i004p00513.

Burns, A. G., W. Wang, L. Qian, S. C. Solomon, Y. Zhang, L. J. Paxton, and X. Yue (2014), On the solar cycle variation of the winter anomaly, J. Geophys. Res. Space Physics, 119, 4938-4949, doi:10.1002/2013JA019552.

Carlson, H. C., K. Oksavik, J. Moen, A. P. van Eyken, and P. Guio (2002), ESR mapping of polar cap patches in the dark cusp, Geophys. Res. Lett., 29(10), 1386, doi:10.1029/2001GL014087.

Carlson, H. C. (2012), Sharpening our thinking about polar cap ionospheric patch morphology, research, and mitigation techniques, Radio Sci., 47, RSOL21, doi:10.1029/2011RS004946.

Crowley, G., T. J. Immel, C. L. Hackert, J. Craven, and R. G. Roble (2006), Effect of IMF BY on thermospheric composition at high and middle latitudes: 1. Numerical experiments, J. Geophys. Res., 111, A10311, doi: 10.1029/2005JA011371.

David, M., J. J. Sojka, R. W. Schunk, and A. J. Coster (2016), Polar cap patches and the tongue of ionization: A survey of GPS TEC maps from 2009 to 2015, Geophys. Res. Lett., 43, 2422-2428, doi:10.1002/2016GL068136.

de la Beaujardiere, O., V. B. Wickwar, G. Caudal, J. M. Holt, J. D. Craven, L. A. Frank, L. H. Brace, D. S. Evans, J. D. Winningham, and R. A. Heelis (1985), Universal time dependence of nighttime F region densities at high latitudes, J. Geophys. Res., 90, 4319.

Deng, Y., and A. J. Ridley (2006), Role of vertical ion convection in the high-latitude ionospheric plasma distribution, J. Geophys. Res., 111, A09314, doi:10.1029/2006JA011637.

Gasda, S., and A. D. Richmond (1998), Longitudinal and interhemispheric variations of auroral ionospheric electrodynamics in a realistic geomagnetic field, J. Geophys. Res., 103, 4011.

Hagan, M. E., and J. M. Forbes (2002), Migrating and nonmigrating diurnal tides in the middle and upper atmosphere excited by tropospheric latent heat release, J. Geophys. Res., 107(D24), 4754, doi:10.1029/2001JD001236. 
445

446

447

448

449

450

451

452

453

454

455

456

457

458

459

460

461

462

463

464

465

466

467

468

469

470

471

472

473

474

475

476

477

478

479

480

481

482

483

484

485

486

487

488

489
Heelis, R. A. (1984), The effects of interplanetary magnetic field orientation on dayside high-latitude ionospheric convection, J. Geophys. Res., 89(A5), 2873-2880, doi:10.1029/JA089iA05p02873.

Heelis, R. A., J. J. Sojka, M. David, and R. W. Schunk (2009), Storm time density enhancements in the middle-latitude dayside ionosphere, J. Geophys. Res., 114, A03315, doi:10.1029/2008JA013690.

Heppner, J. P. (1977), Empirical models of high-latitude electric fields, J. Geophys. Res., $82,1115-1125$.

Immel, T. J., J. D. Craven, and L. A. Frank (1997), Influence of IMF By on large-scale decreases of O column density at middle latitudes, J. Atmos. Sol. Terr. Phys., 59, $725-737$.

Liu, J., Zhao, B., and Liu, L. (2010), Time delay and duration of ionospheric total electron content responses to geomagnetic disturbances, Ann. Geophys., 28, 795805, doi:10.5194/angeo-28-795-2010.

Liu, J., L. Liu, B. Zhao, J. Lei, J. P. Thayer, and R. L. McPherron (2012a), Superposed epoch analyses of thermospheric response to CIRs: Solar cycle and seasonal dependencies, J. Geophys. Res., 117, A00L10, doi: 10.1029/2011JA017315.

Liu, J., L. Liu, B. Zhao, and W. Wan (2012b), Influence of interplanetary solar wind sector polarity on the ionosphere, J. Geophys. Res., 117, A08335, doi: 10.1029/2012JA017859.

Liu, J., T. Nakamura, L. Liu, W. Wang, N. Balan, T. Nishiyama, M. R. Hairston, and E. G. Thomas (2015), Formation of polar ionospheric tongue of ionization during minor geomagnetic disturbed conditions, J. Geophys. Res. Space Physics, 120, doi:10.1002/2015JA021393.

Liu, J., W. Wang, A. Burns, X. Yue, S. Zhang, Y. Zhang, and C. Huang (2016a), Profiles of ionospheric storm-enhanced density during the 17 March 2015 great storm, J.

Geophys. Res. Space Physics, 121, doi: 10.1002/2015JA021832.

Liu, J., W. Wang, A. Burns, S. C. Solomon, S. Zhang, Y. Zhang, and C. Huang (2016b), Relative Importance of Horizontal and Vertical Transports to the Formation of Ionospheric Storm-enhanced Density and Polar Tongue of Ionization, J. Geophys. Res. Space Physics, 121, doi:10.1002/2016JA022882.

Lockwood, M., and H. C. Carlson (1992), Production of polar cap electron density patches by transient magnetopause reconnection, Geophys. Res. Lett., 19(17), 1731-1734, doi:10.1029/92GL01993.

McHarg, M., F. Chun, D. Knipp, G. Lu, B. Emery, and A. Ridley (2005), High-latitude Joule heating response to IMF inputs, J. Geophys. Res., 110, A08309, doi: 10.1029/2004JA010949.

Milan, S. E., M. Lester, and T. K. Yeoman (2002), HF radar polar patch formation revisited: Summer and winter variations in dayside plasma structuring, Ann. Geophys., 20, 487-499, doi:10.5194/angeo-20-487-2002.

Potemra, T. A., L. J. Zanetti, P. F. Bythrow, A. T. Y. Lui, and T. Iijima (1984), Bydependent convection patterns during northward interplanetary magnetic field, J. Geophys. Res., 89, 9753.

Prolss, G. W. (1995), Ionospheric F-region storms, in handbook of Atmospheric electrodynamics, 2, 195, CRC press, Boca Ration, Fla. 
490

491

492

493

494

495

496

497

498

499

500

501

502

503

504

505

506

507

508

509

510

511

512

513

514

515

516

517

518

519

520

521

522

523

524

525

526

527

528

529

530

531

532

533

534

Qian, L., A. G. Burns, B. A. Emery, B. Foster, G. Lu, A. Maute, A. D. Richmond, R. G. Roble, S. C. Solomon, and W. Wang (2014), The NCAR TIE-GCM, in Modeling the Ionosphere-Thermosphere System, edited by J. Huba R. Schunk and G. Khazanov, pp. 73-83, John Wiley, Chichester, U. K., doi:10.1002/9781118704417.ch7.

Richmond, A. D., E. C. Ridley, and R. G. Roble (1992), A thermosphere/ionosphere general circulation model with coupled electrodynamics, Geophys. Res. Lett., 19, 601-604, doi:10.1029/92GL00401.

Richmond, A. D., C. Lathuille`re, and S. Vennerstroem, Winds in the high-latitude lower thermosphere: Dependence on the interplanetary magnetic field (2003), J. Geophys. Res., 108(A2), 1066, doi: 10.1029/2002JA009493.

Rishbeth, H., and O. K. Garriott (1969), Introduction to Ionospheric Physics, Academic Press, New York.

Roble, R. G., E. C. Ridley, A. D. Richmond, and R. E. Dickinson (1988), A coupled thermosphere/ionosphere general circulation model, Geophys. Res. Lett., 15, 13251328, doi:10.1029/GL015i012p01325.

Rodger, A., M. Pinnock, J. Dudeney, K. Baker, and R. Greenwald (1994), A new mechanism for polar patch formation, J. Geophys. Res., 99, 6425-6436, doi:10.1029/93JA01501.

Ruohoniemi, J. M., and R. A. Greenwald (2005), Dependencies of high-latitude plasma convection: Consideration of interplanetary magnetic field, seasonal, and universal time factors in statistical patterns, J. Geophys. Res., 110, A09204, doi:10.1029/2004JA010815.

Sato, T. (1959), Morphology of ionospheric F2 disturbances in the polar regions: A linkage between polar patches and plasmaspheric drainage plumes, Rep. Ionos. Res. Space Res. Jpn., 131, 91-101. Sato, T., and G. F. Rourke (1964), F-region enhancements in the Antarctic, J. Geophys. Res., 69(21), 4591-4607, doi:10.1029/JZ069i021p04591.

Sojka, J. J., M. D. Bowline, R. W. Schunk, D. T. Decker, C. E. Valladares, R. Sheehan, D. N. Anderson, and R. A. Heelis (1993), Modeling polar cap F-region patches using time varying convection, Geophys. Res. Lett., 20(17), 1783-1786, doi:10.1029/93GL01347.

Sojka, J. J., M. D. Bowline, and R. W. Schunk (1994), Patches in the polar ionosphere: UT and seasonal dependence, J. Geophys. Res., 99, 14,959-14,970, doi:10.1029/93JA03327.

Sojka, J. J., M. David, R. W. Schunk, and R. A. Heelis (2012), A modeling study of the longitudinal dependence of storm time midlatitude dayside total electron content enhancements, J. Geophys. Res., 117, A02315, doi:10.1029/2011JA017000.

Sojka, J. J., R. W. Schunk, W. R. Hoegy, and J. M. Grebowsky (1991), Model and observation comparison of the universal time and IMF BY dependence of the ionospheric polar hole, Adv. Space Res., 11(10), 39-42.

Thayer, J. P., T. L. Killeen, F. G. McCormac, C. R. Tschan, J.-J. Ponthieu, and N. W. Spencer (1987), Thermospheric neutral wind signatures dependent on the east-west component of the interplanetary magnetic field for northern and southern hemispheres as measured from Dynamics Explorer-2, Ann. Geophys., 5A, 363-368. 
Wang, W., T. L. Killeen, A. G. Burns, and R. G. Roble (1999), A high-resolution, three dimensional, time dependent, nested grid model of the coupled thermosphereionosphere, J. Atmos. Sol. Terr. Phys., 61, 385-397.

Weimer, D. R. (1995), Models of the high-latitude electric potential derived with a least error fit of spherical harmonic coefficients, J. Geophys. Res., 100, 19,595-19,608.

Weimer, D. R. (1996), A flexible, IMF dependent model of high-latitude electric potential having "space weather" applications, Geophys. Res. Lett., 23, 2549.

Weimer, D. R. (2005), Improved ionospheric electrodynamic models and application to calculating Joule heating rates, J. Geophys. Res., 110, A05306, doi:10.1029/2004JA010884.

Xu, J., W. Wang, and H. Gao (2013), The longitudinal variation of the daily mean thermospheric mass density, J. Geophys. Res. Space Physics, 118, 515-523, doi:10.1029/2012JA017918.

Zhang, Q. H., et al. (2011), On the importance of interplanetary magnetic field $|\mathrm{By}|$ on polar cap patch formation, J. Geophys. Res., 116, A05308, doi:10.1029/2010JA016287.

\section{Figures}

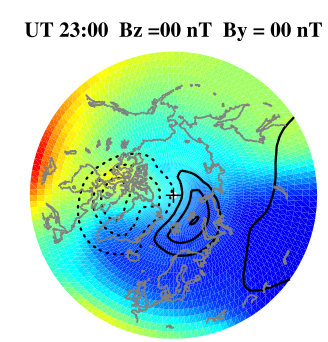

UT 02:00 Bz $=-10$ nT By $=00$ nT

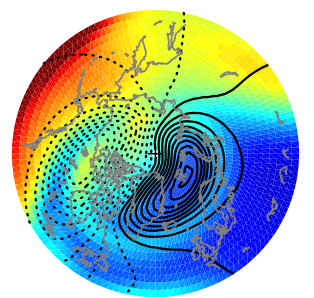

UT 05:00 Bz $=-10$ nT By $=00$ nT

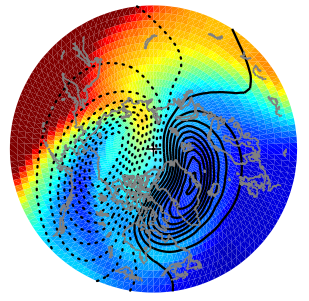

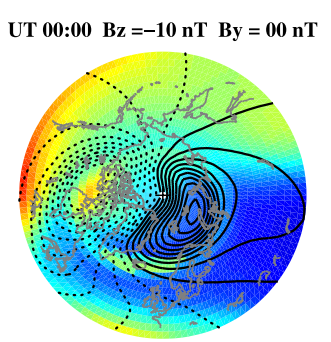

UT 03:00 Bz $=-10$ nT $B y=00$ nT

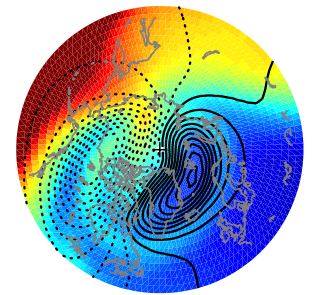

UT 06:00 Bz $=-10$ nT By $=00$ nT

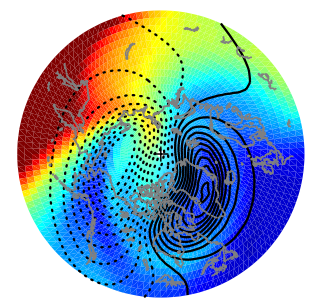

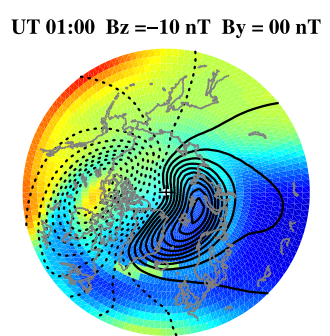

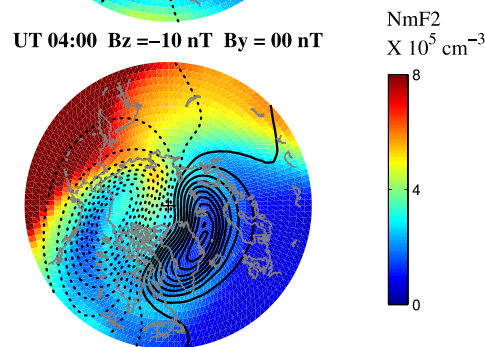

UT 07:00 Bz $=-10$ nT $\quad B y=00$ nT

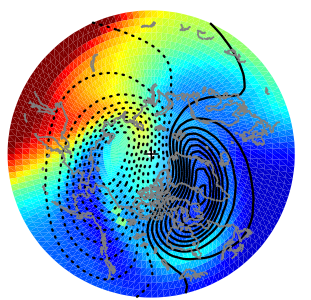

555 Figure 1. A polar view of the $\mathrm{N}_{\mathrm{m}} \mathrm{F}_{2}$ evolution in geographic coordinates in the Northern 
556 Hemisphere. Superimposed is the electrostatic potential. The outer circle is $40^{\circ}$ in

557 geographic latitude.

558

559
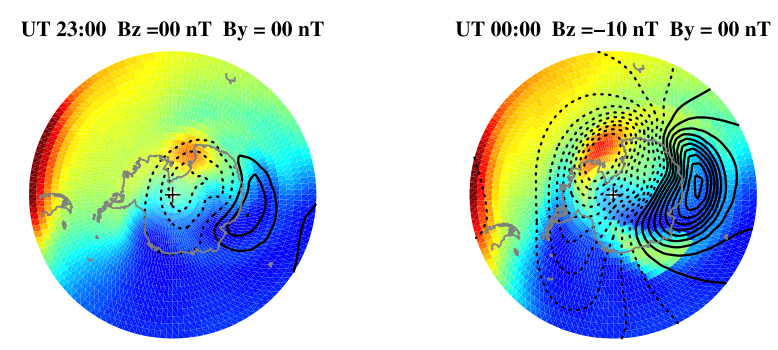

UT 02:00 Bz=-10 nT By $=00 \mathrm{nT}$
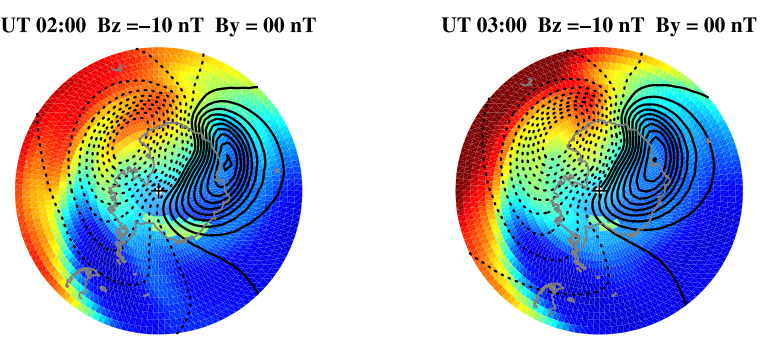

UT 05:00 Bz $=-10 \mathrm{nT} \quad \mathrm{By}=00 \mathrm{nT}$
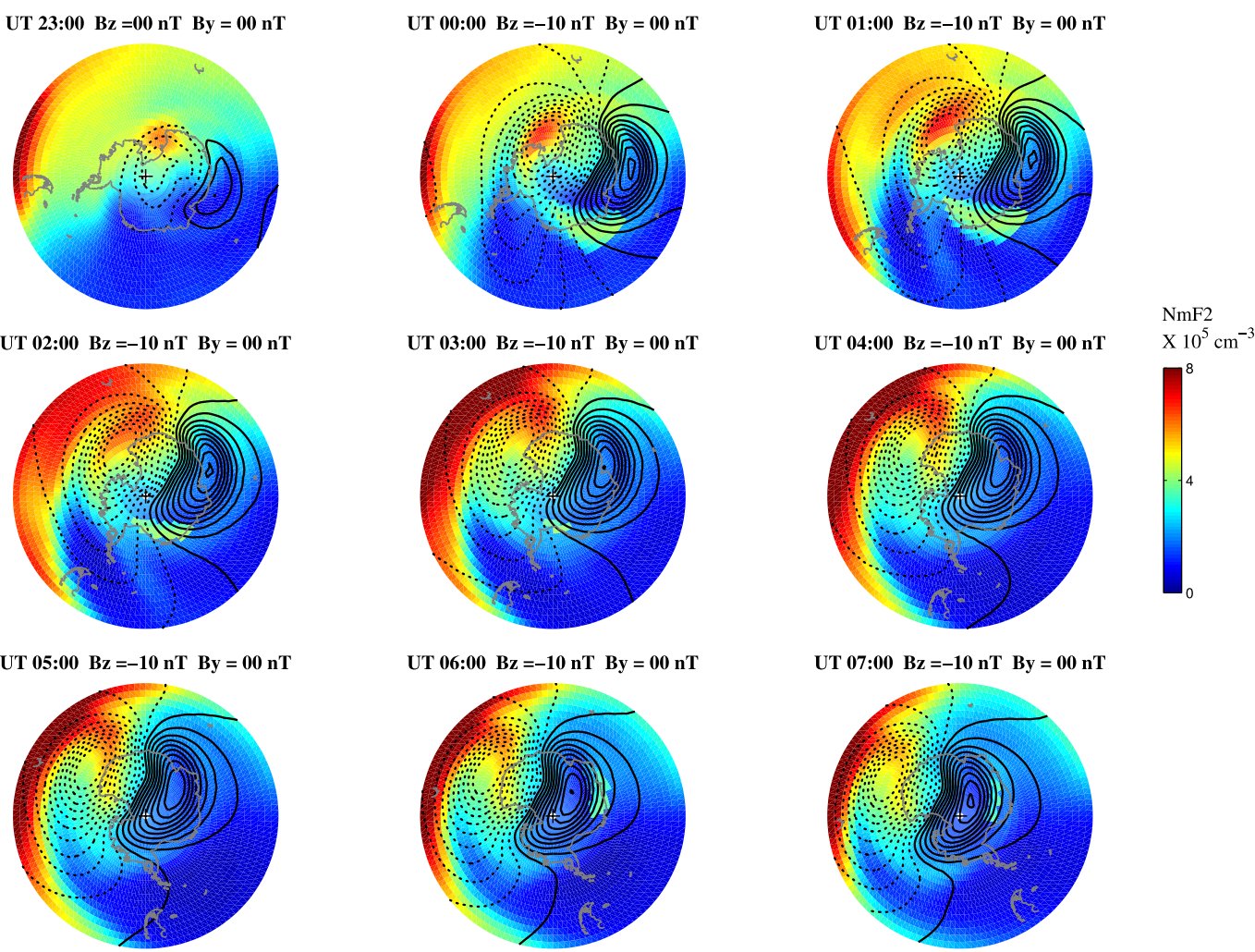

UT 07:00 Bz $=-10 \mathrm{nT} \quad \mathrm{By}=00 \mathrm{nT}$

560

561 Figure 2. Same as Figure 1, but for the Southern Hemisphere.

562

563 

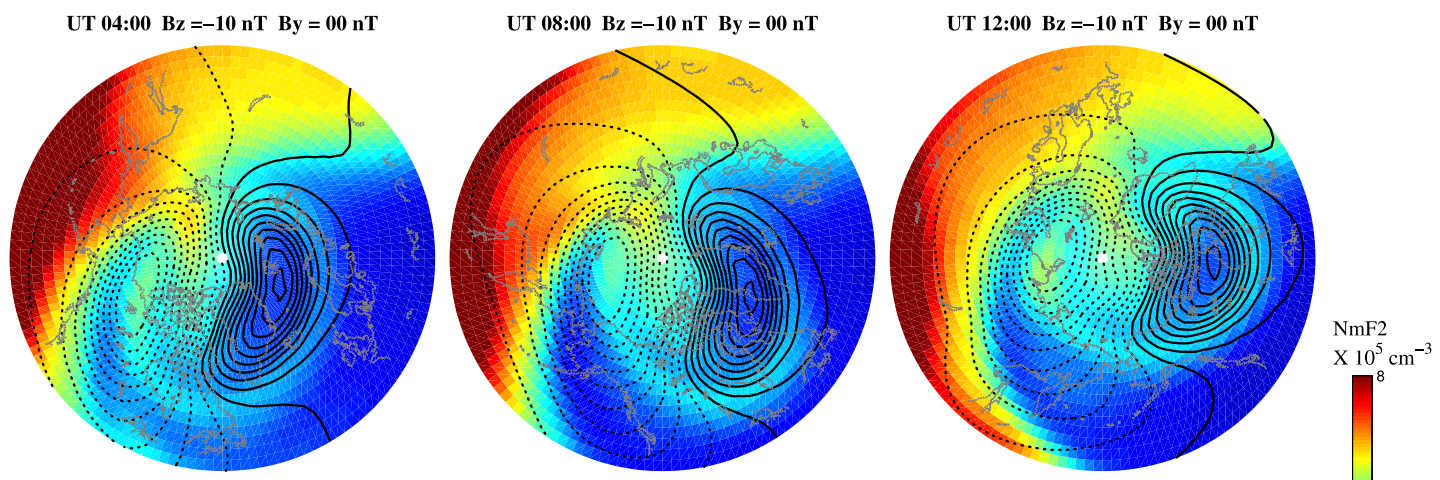

564
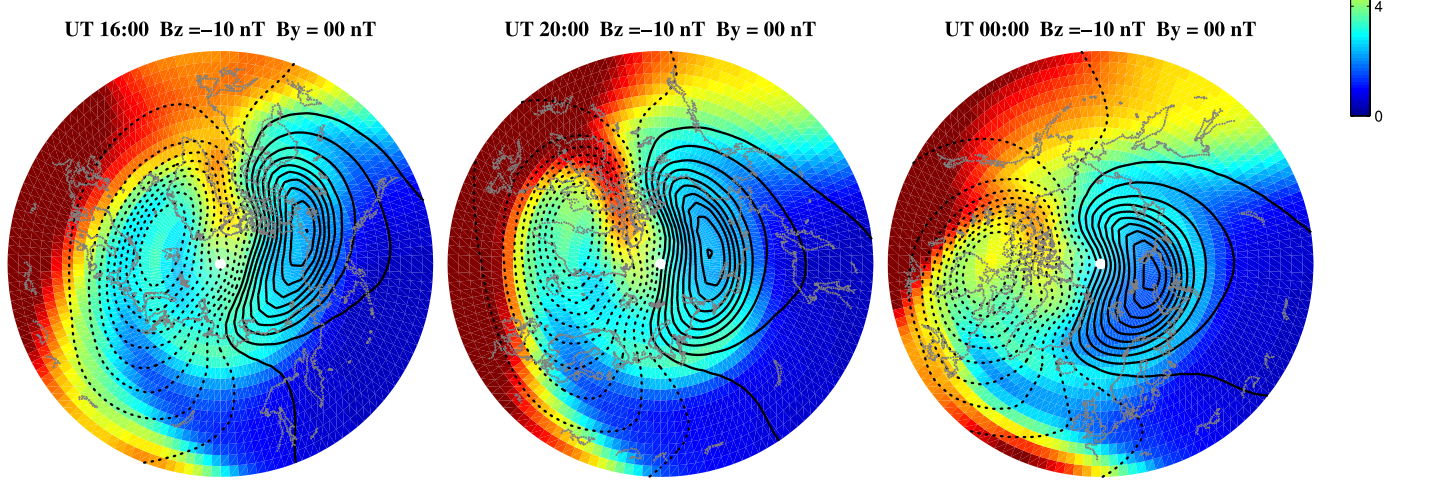

565 Figure 3. UT Dependence of TOIs for the Northern Hemisphere after 4 hours of constant

566 southward IMF Bz (- $10 \mathrm{nT})$ conditions.

567

568 

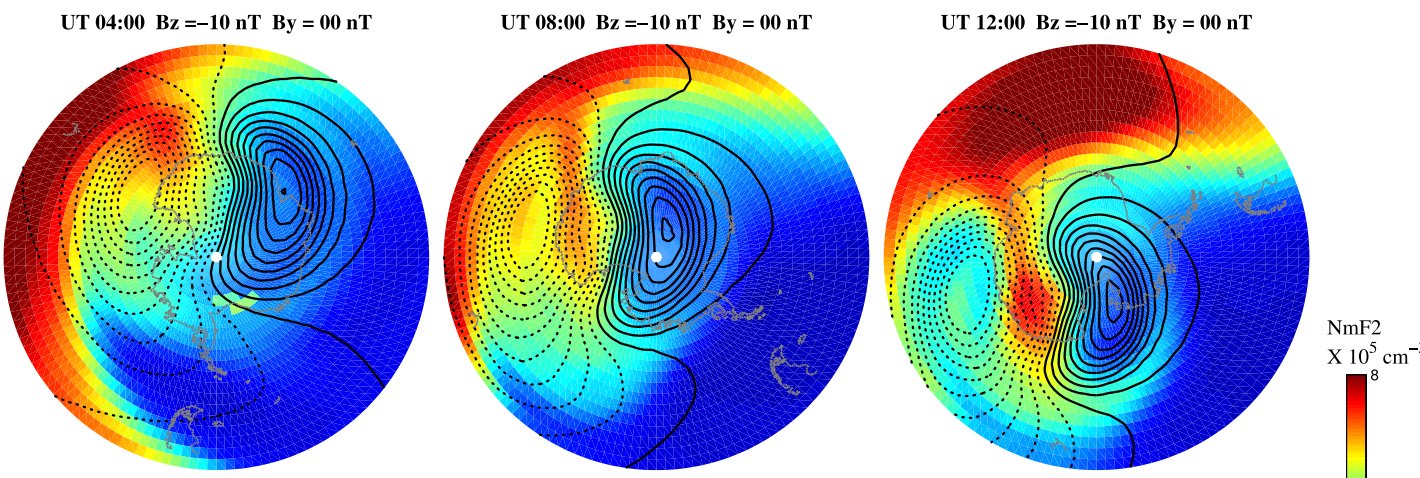

UT 16:00 Bz=-10 nT By $=00 \mathrm{nT}$
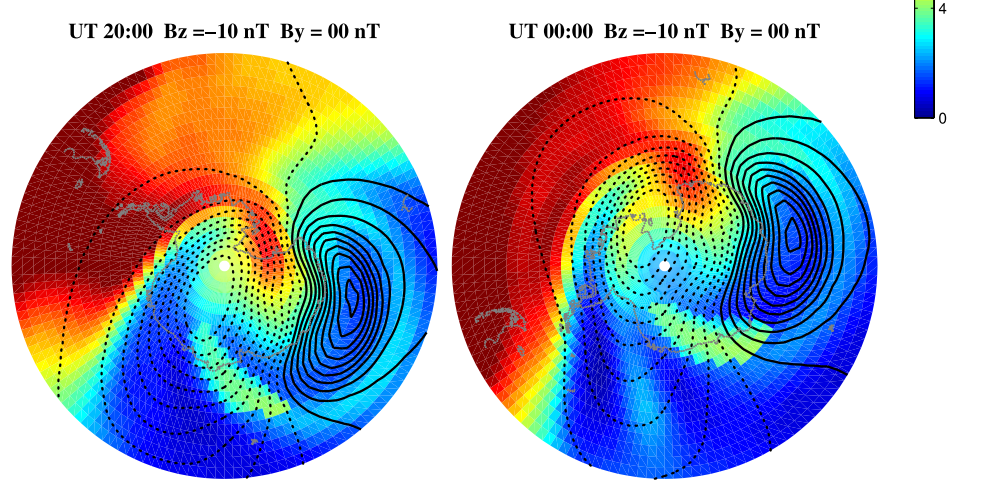

569

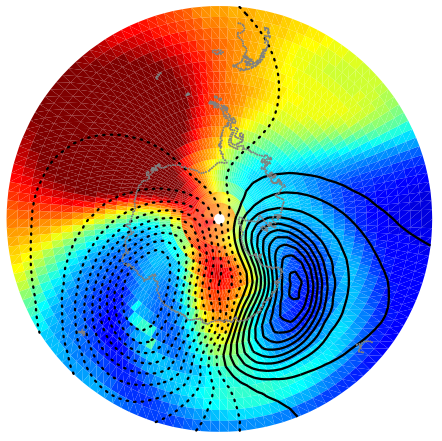

570 Figure 4. Same as Figure 3, but for the Southern Hemisphere.

571

572

573

574 


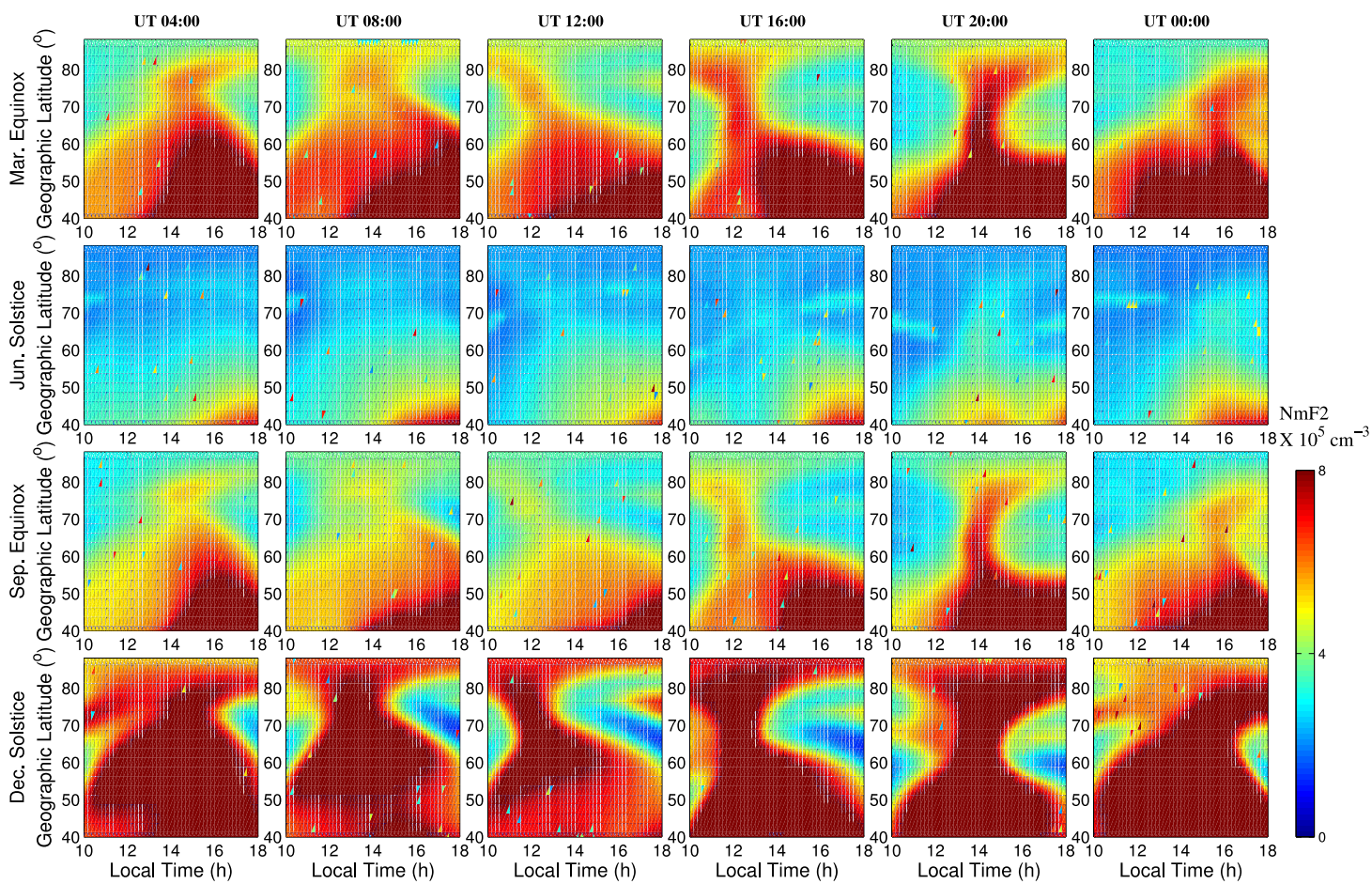

576 Figure 5. Seasonal dependence of UT effects on the TOI in the NH. IMF Bz= $-10 \mathrm{nT}$ and

$577 \quad \mathrm{By}=0 \mathrm{nT}$ are used for this seasonal analysis.

578

579

580 

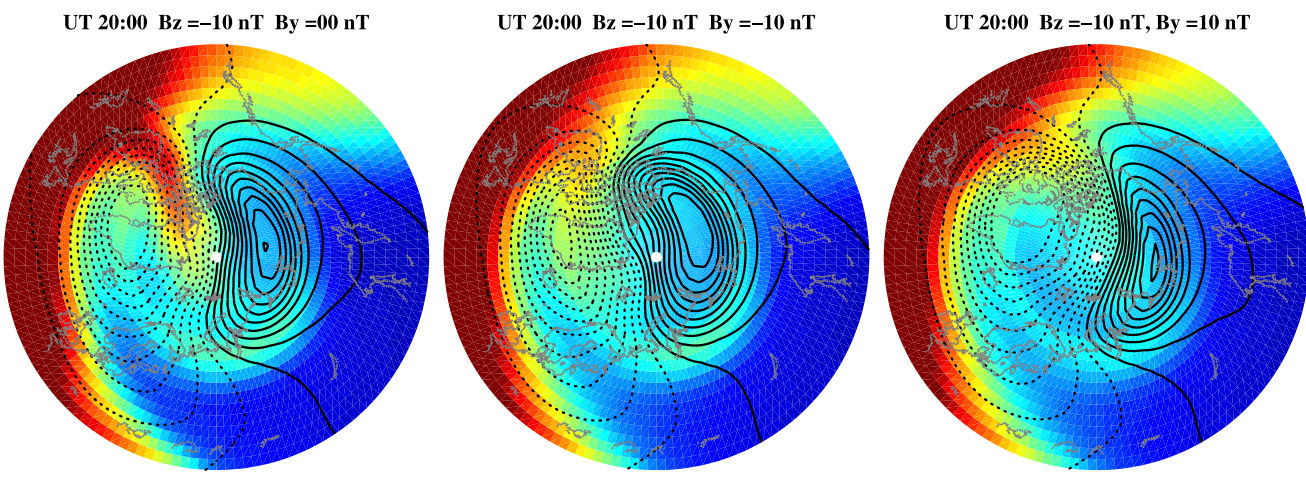

$\mathrm{NmF} 2$
$\mathrm{X} 10^{5} \mathrm{~cm}^{-3}$
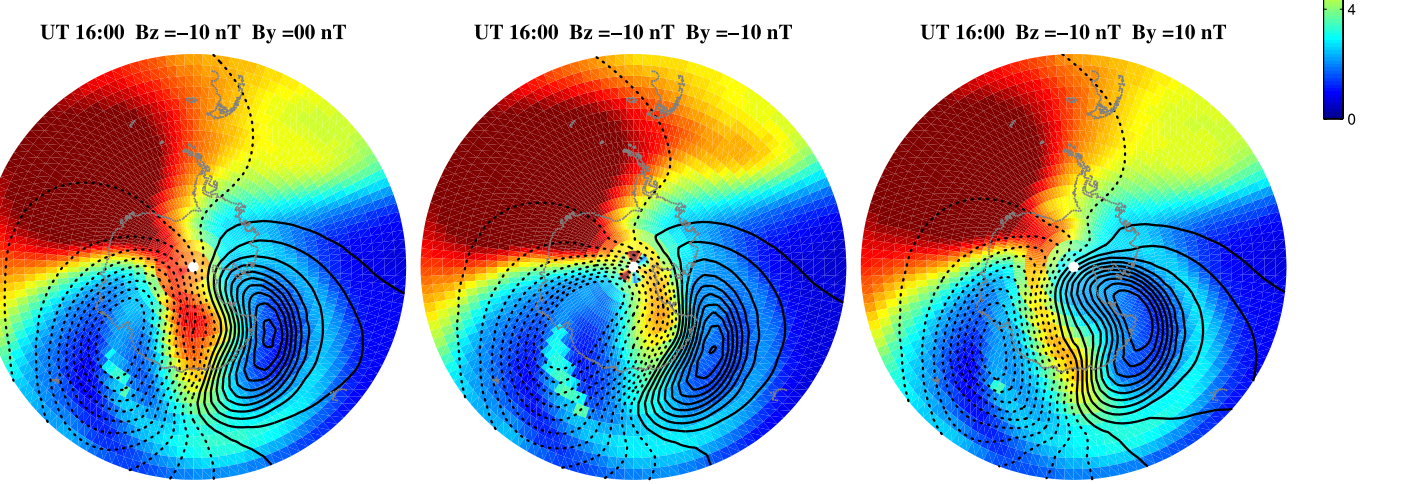

581

582 Figure 6. IMF By dependency of TOIs for southward IMF Bz. The top panels are for the

583 Northern Hemisphere at 2000 UT and the bottom panels are for the Southern Hemisphere

584 at $1600 \mathrm{UT}$.

585

586

587 

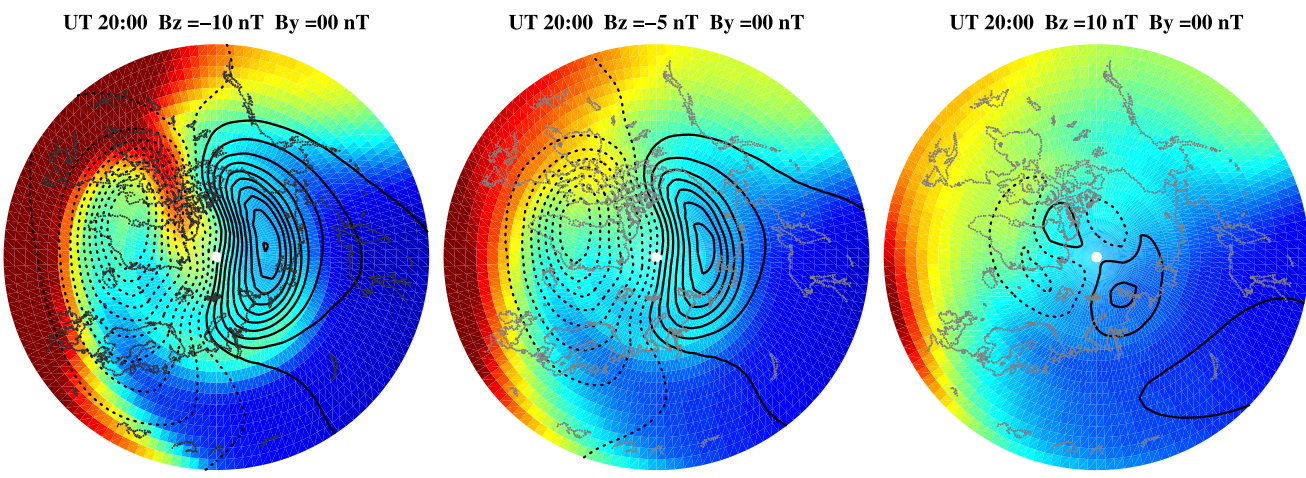

$\mathrm{NmF} 2$
$\mathrm{X} 10^{5} \mathrm{~cm}^{-3}$

UT 20:00 Bz $=-10 \mathrm{nT} \quad \mathrm{By}=00 \mathrm{nT}$

588
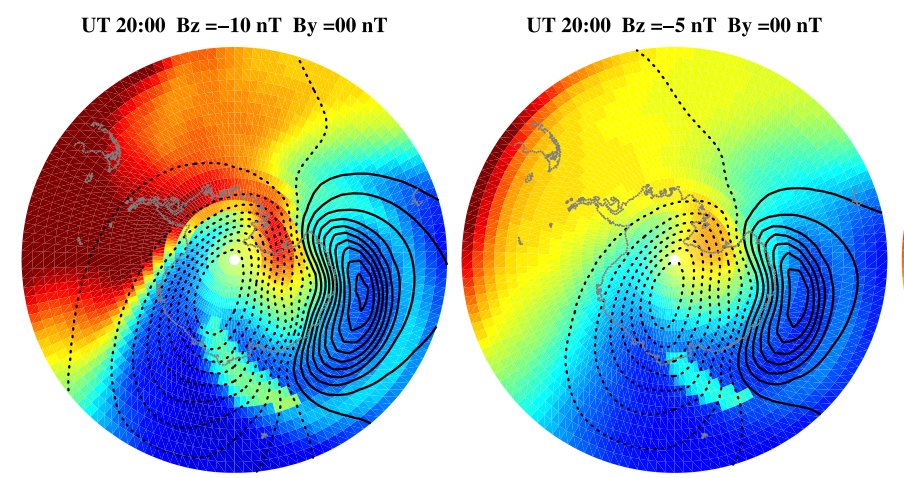

UT 20:00 Bz=10 nT By $=00$ nT

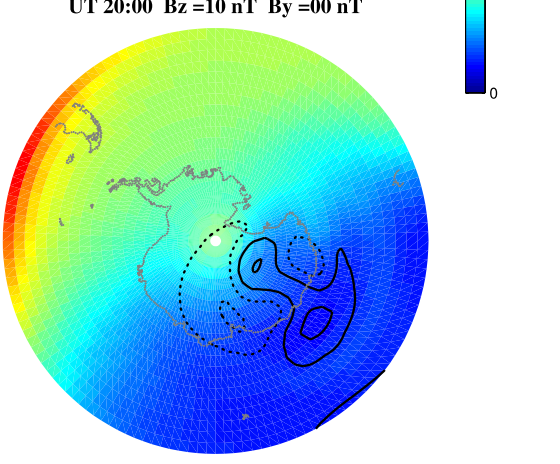

589 Figure 7. IMF Bz dependency of TOIs at 2000 UT. The top panels are for the Northern

590 Hemisphere and the bottom panels are for the Southern Hemisphere.

591

592

593 
594
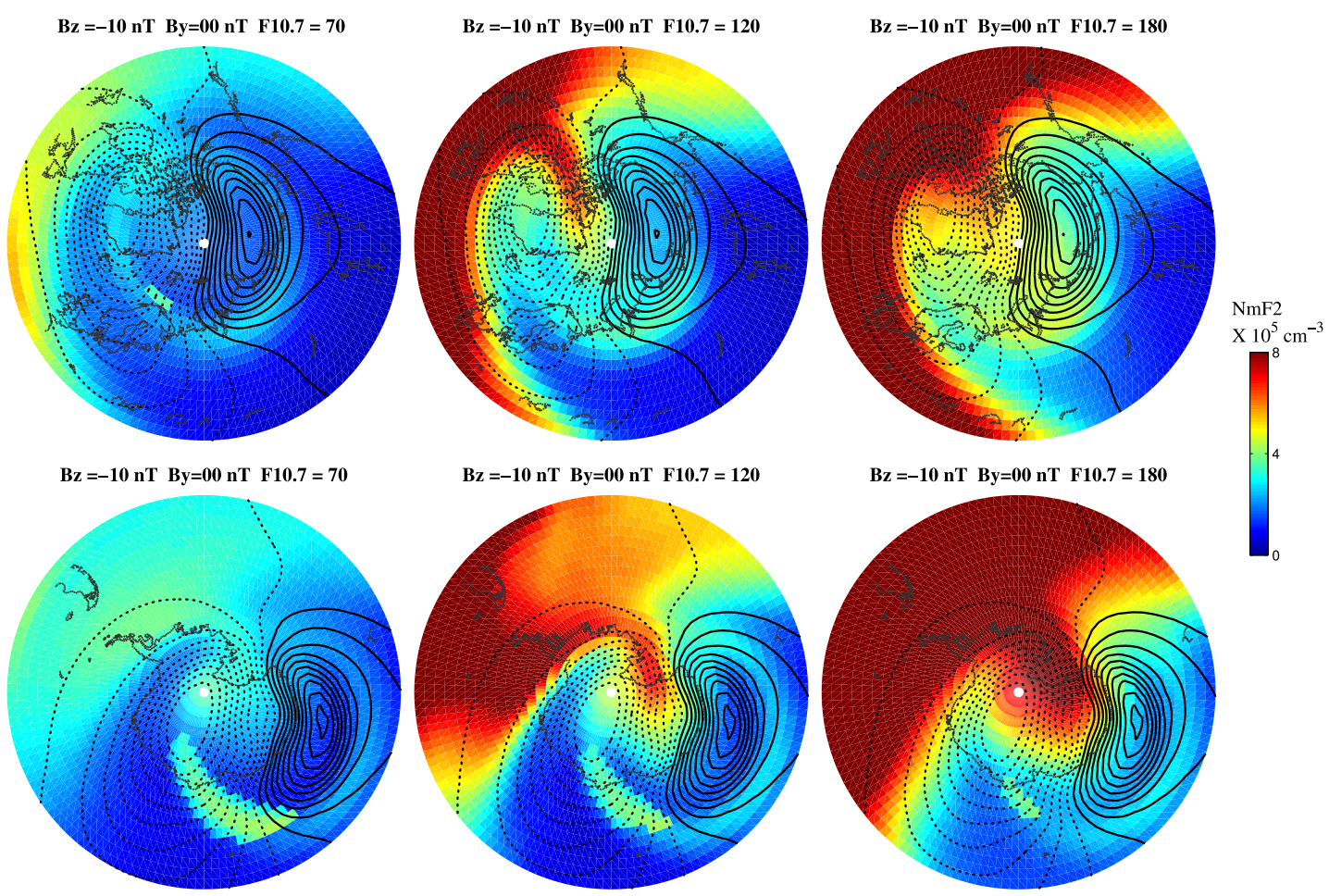

596 Figure 8. Solar activity dependence of TOI for Southward IMF Bz at 2000 UT. 


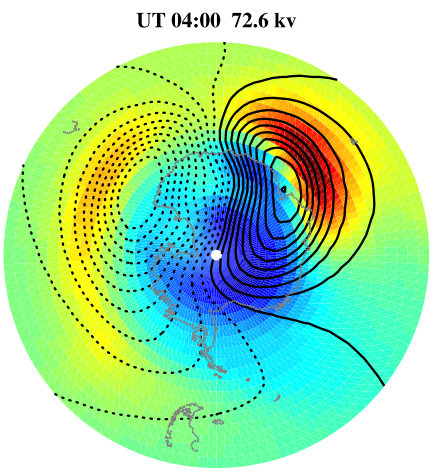

UT 16:00 73.4 kv

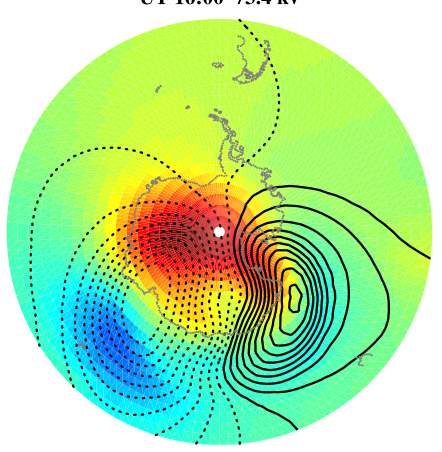

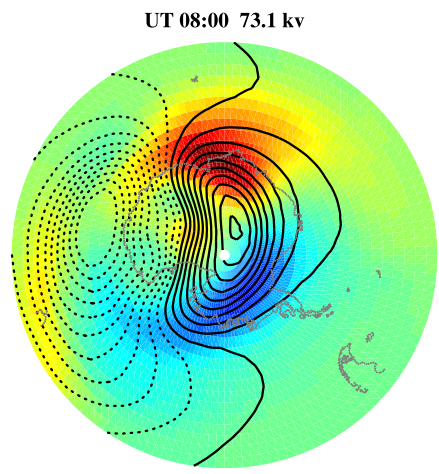

UT 20:00 $73.3 \mathrm{kv}$

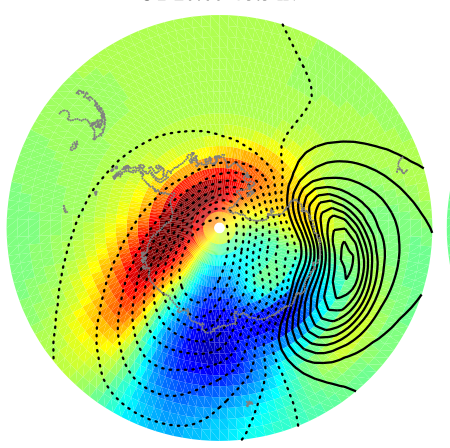

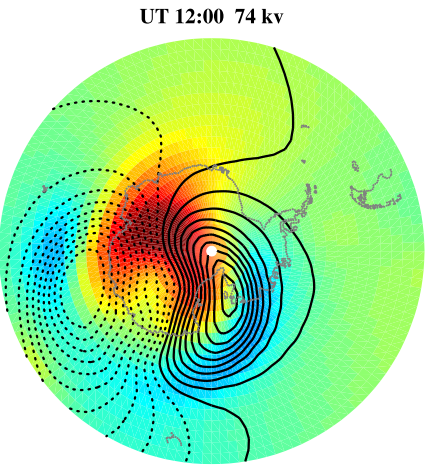

UT 00:00 73.9 kv

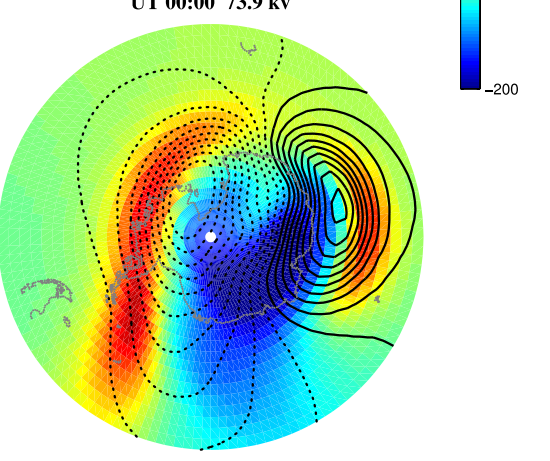

600

601

602 Figure 9. UT dependence of polar cap potential (contour line) and upward $\mathbf{E} \times \mathbf{B}$ drifts

603 (contour color) in the Southern Hemisphere at pressure level $3.125(\sim 300 \mathrm{~km})$. Cross

604 polar cap potential drop are labeled in the title.

605

606

607 